Mariana Almeida Hein ${ }^{1}$ Sérgio Seiji Aragaki ${ }^{1}$

\section{Saúde e envelhecimento: um estudo de dissertações de mestrado brasileiras (2000-2009)}

\author{
Health and ageing: \\ a study of Brazilian masters dissertations (2000-2009)
}

${ }^{1}$ Faculdade de Medicina, Universidade Federal do Tocantins. 109 Norte, Avenida NS 15, ALCNO 14, Bloco BALA, sala 18. 77001090 Palmas TO.

mariana.hein@hotmail.com
Abstract The scope of this study was to understand the current discursive practices and meanings that have been produced about the relationship between health and ageing. The study was based on abstracts of dissertations available in the CAPES (Coordination of Personal of Higher Education) portal between 2000 and 2009, accessed by using the following search words: aged, ageing, old age, senescence, the elderly and old people. Based on the material selected, $175 a b$ stracts of papers, in-depth readings were made and analytical categories created. The conclusion was reached that there are several terms used to designate the people in the life cycle under scrutiny: the elderly, old people and senior citizens, with predominance of the first. Although there is still a negative connotation related to the elderly and ageing, this is changing. Several meanings are possible and coexist, forged in accordance with historical, social, economic and cultural factors. Many problems faced by the elderly may be intrinsically related to how they see themselves and are perceived by others. It is therefore essential to affirm and share the positive aspects of being old and the ageing process, ensuring care and protection by the family and society to this social group. Key words The elderly, Ageing, Health of the elderly, Quality of life
Resumo Este trabalho teve como objetivo o entendimento das práticas discursivas e dos sentidos que têm sido produzidos a respeito da relação entre saúde e envelhecimento na atualidade. Teve como base o estudo dos resumos das dissertações disponiveis no portal CAPES, referentes ao período de 2000 a 2009, acessadas por intermédio do uso dos descritores: idoso, envelhecimento, terceira idade, senescência, ancião e velho. A partir do material selecionado, 175 resumos de dissertações, foram feitas leituras aprofundadas e criadas categorias analíticas. Chegou-se à conclusão de que vários são os termos usados para designar as pessoas no ciclo de vida estudado: idoso, velho e terceira idade, com predomínio da primeira. Apesar de prevalecer ainda uma conotação negativa relacionada aos idosos e ao envelhecimento, isso está mudando. Diversos sentidos são possíveis e coexistem, forjados de acordo com fatores históricos, sociais, econômicos e culturais. Muitos problemas enfrentados pelos idosos podem estar intrinsecamente relacionados em como eles se reconhecem e são reconhecidos pelos outros. Assim, é fundamental a afirmação e o compartilhar dos aspectos positivos relacionados aos idosos e ao processo de envelhecer, propiciando-se o cuidado e a proteção da família e da sociedade a esse grupo social. Palavras-chave Idoso, Envelhecimento, Saúde do idoso, Qualidade de vida 


\section{Introdução}

As questões referentes à velhice e ao processo de envelhecimento têm despertado cada vez mais interesse da sociedade de um modo geral, em função do acelerado processo de envelhecimento populacional que vem ocorrendo em vários países, inclusive no Brasil. É possível dizer que isto se deve, basicamente, à redução da taxa de natalidade e ao aumento da expectativa de vida, proporcionada por inúmeros avanços tecnológicos em diversos campos científicos.

O envelhecimento faz parte da vida humana e vários autores têm se dedicado ao estudo desse processo, assim como a respeito dos idosos. Para Bosi1: "Além de ser um destino do indivíduo, a velhice é uma categoria social. [...] cada sociedade vive de forma diferente o declínio biológico do homem. A sociedade industrial é maléfica para a velhice. Nas sociedades mais estáveis um octogenário pode começar a construção de uma casa, a plantação de uma horta, pode preparar os canteiros e semear um jardim. Seu filho continuará a obra". Outro estudioso de importância é Hall², sendo que, de acordo com esse autor, a velhice é um estágio de desenvolvimento em que as paixões da juventude e os esforços de uma carreira atingiriam fruição e consolidação.

Já, segundo Papalia e Olds ${ }^{3}$, possuir idade avançada no Japão pode trazer um certo glamour, havendo então um tratamento melhor a essas pessoas por parte de serviços e empresas. Por outro lado, as autoras afirmam que nos Estados Unidos, assim como no mundo ocidental em geral, circulam sentidos díspares sobre o envelhecimento: ora é arguido com sentido negativo, tendo conotação de "antessala" para a morte; ora como positivo, sendo considerada a "melhor idade".

Além desses, outros autores merecem destaque no assunto. Neri e Debert ${ }^{4}$ afirmam: "A velhice e o envelhecimento, portanto são realidades heterogêneas, isto é, variam conforme os tempos históricos, as culturas e subculturas, as classes sociais, as histórias de vida pessoais, as condições educacionais, os estilos de vida, os gêneros, as profissões e as etnias, dentre outros elementos que conformam as trajetórias de vida dos indivíduos e grupos".

Debert $^{5}$, em outra obra, ainda acrescenta: "A tendência contemporânea é rever os estereótipos associados ao envelhecimento. A ideia de um processo de perdas tem sido substituída pela consideração de que os estágios mais avançados da vida são momentos propícios para novas conquistas, guiadas pela busca do prazer e da satisfação pessoal. As experiências vividas e os saberes acumulados são ganhos que oferecem oportunidades de realizar projetos abandonados em outras etapas e estabelecer relações mais profícuas com o mundo dos mais jovens e dos mais velhos."

Percebe-se, então, que os fenômenos da velhice e do envelhecimento trazem uma série de implicações, não só pessoais como também familiares, sociais, culturais, políticas e econômicas. Sendo assim, para que se efetuem as mudanças necessárias nessas múltiplas esferas envolvidas, é preciso considerar, ainda, a variedade de contextos existentes na realidade mundial, dada a sua grande diversidade. Não há, portanto, uma resposta única e pronta às questões referentes à terceira idade, pois o próprio fenômeno da velhice tem múltiplos sentidos, sendo conhecimentos situados ${ }^{6}$, construções sociais que são fruto das interações entre humanos em contextos histórico-sociais específicos?

Há vários termos para denominar as pessoas que estão no ciclo de vida em questão, surgidos em épocas diferentes, com conotações também distintas. Assim, sabe-se que o termo velho é historicamente ligado a sentidos negativos, tais como inativo, improdutivo, inválido, ultrapassado, despossuído, feio, ruim e sem status social. O termo idoso, em antítese, se refere a uma pessoa respeitada, valorizada devido, entre outras coisas, ao recebimento de pensão ou aposentadoria. Terceira idade, por sua vez, surge no Brasil na década de 1980 , sendo relacionada a pessoas aposentadas consideradas dinâmicas, de 60 a 80 anos de idade, entendidos como "jovens idosos", sem sinais de decrepitude ou senilidade, implicando em uma imagem positiva e bastante consumista, uma vez que busca retardar e negar a velhice por meio do uso de produtos estéticos, medicamentos e cirurgias plásticas ${ }^{8,9}$.

Apesar das diferenças de sentidos relacionados aos termos velho, idoso e membro da terceira idade, sabe-se que muitas vezes eles são utilizados indistintamente, como se fossem sinônimos. Por isso, no presente trabalho será feita a opção pelo uso do termo idoso, uma vez que este traz conotações positivas relacionadas a essas pessoas e por ter sido adotado por documentos oficiais brasileiros, tais como a Política Nacional do Idoso $^{10}$, a Política Nacional de Saúde da Pessoa Idosa $^{11}$ e o Estatuto do Idoso ${ }^{12}$.

O presente trabalho será dedicado ao estudo das práticas discursivas e dos sentidos que têm sido produzidos a respeito do envelhecimento e de sua relação com a saúde das pessoas idosas. 
Práticas discursivas são linguagens em ação, ou seja, "as maneiras a partir das quais as pessoas produzem sentidos e se posicionam em relações sociais cotidianas" 13 .

Para o alcance do presente objetivo foi feito um estudo tendo como base os títulos e os resumos das dissertações de mestrado disponíveis no portal CAPES, durante o período 2000-2009. Este material foi considerado documento de domínio público, sendo que Peter Spink ${ }^{13}$ assim os define: "os documentos de domínio público, como registros, são documentos tornados públicos, sua intersubjetividade é produto da interação com um outro desconhecido, porém significativo e frequentemente coletivo. São documentos que estão à disposição, simultaneamente traços de ação social e a própria ação social”. Este estudo poderá colaborar para se conhecer com mais profundidade o envelhecimento para então contribuir com o alcance de uma melhor qualidade de vida para essa população.

Este trabalho tem como objetivo o entendimento das práticas discursivas e dos sentidos que têm sido produzidos a respeito da relação entre saúde e envelhecimento em dissertações de mestrado disponíveis no portal CAPES no período 2000-2009.

\section{Métodos}

Inicialmente foram definidos, por meio de pesquisa na Biblioteca Virtual em Saúde (BVS), quais os descritores que melhor se adequavam à pesquisa. A escolha desses termos foi feita tendo como base os Descritores em Ciências da Saúde (DeCS) da BVS, ou seja, um vocabulário estruturado criado pela BIREME para servir como uma linguagem única na indexação de artigos de revistas científicas, livros, anais de congressos, relatórios técnicos e outros tipos de materiais. Assim, foi feito um levantamento de todas as palavras relacionadas ao envelhecimento humano nessa ferramenta, sendo escolhidos os descritores: idoso, envelhecimento e velho.

Com os descritores definidos, passou-se à próxima etapa da pesquisa. No portal de dissertações da CAPES foram estabelecidos os limites da busca: trabalhos publicados em português no período de 2000 a 2009. Durante o processo de pesquisa observou-se que haviam alguns termos relacionados ao envelhecimento e que, apesar de não serem descritores da BVS, também recuperavam dissertações de importância à pesquisa e que por isso foram adicionados: terceira idade, senescência e ancião. Em seguida, o levantamento foi realizado a partir de cada descritor selecionado, tendo-se como resultado as dissertações de mestrado disponíveis no referido banco de dados, sendo que foi obtido um total de 9.415.

Após essa etapa foi realizada a leitura e a seleção dos materiais pelos títulos e, em seguida, pelos resumos das dissertações, tarefa necessária, pois, apesar do uso dos descritores, foi obtido muito material que não condizia com o presente propósito, uma vez que tratavam de assuntos relacionados a aspectos parciais (doenças, por exemplo) e não às pessoas idosas em si. Também permitiu trabalhar somente com as dissertações que trouxessem versões a respeito da relação entre saúde e envelhecimento, e que permitissem explicar os sentidos presentes a respeito da velhice na atualidade. Terminadas todas as etapas descritas obteve-se, por fim, 175 resumos de dissertações de mestrado do portal CAPES, no período 2000-2009, compondo, então, os documentos da presente pesquisa.

A seguir foi realizada a análise, por meio da leitura aprofundada, diversas vezes, do material selecionado, o que permitiu identificar não somente o que tem sido produzido a respeito do processo de envelhecimento e dos idosos, mas também criar categorias analíticas, as quais permitiram entender e explicar os diferentes sentidos construídos a respeito da temática no período delimitado.

\section{Resultados e discussão}

O total de dissertações encontradas na pesquisa junto ao Portal CAPES foi de 9.415, distribuídas entre os descritores envelhecimento, velho, idoso, terceira idade, senescência e ancião. Conforme apontado na seção anterior, somente 175 trabalhos foram selecionados, por cumprirem os critérios de inclusão na pesquisa. Destes, 80 referiam-se ao descritor envelhecimento; 59 ao idoso; 23 ao velho; 10 ao terceira idade; dois ao ancião; e um ao senescência. De maneira geral, observouse que, o número de dissertações aumentou bastante se comparando os anos de 2000 e 2009, passando de 578 a 1338, demarcando o aumento do interesse pelo estudo da população em questão.

Houve grande diversidade relacionada aos interlocutores (sujeitos) da pesquisa, sendo que, predominantemente, foram entrevistados idosos (115 dissertações; 103 os utilizando como única fonte de estudo e as demais colhendo também discursos de pessoas de outros ciclos de vida, além 
de documentos de domínio público). Dezesseis dissertações foram baseadas exclusivamente em entrevistas realizadas com crianças, adolescentes e/ou adultos, considerando-se três que ouviram familiares e duas, a comunidade da qual os idosos faziam parte. Estudantes universitários também foram ouvidos, totalizando cinco dissertações (Enfermagem, Educação Física e Medicina, Educação Física, Pedagogia e de diversos cursos). Profissionais da área da Saúde foram entrevistados em onze estudos (três de Enfermagem, um de Gerontologia e os demais com diversos profissionais). Representantes de entidades foram interlocutores em dois trabalhos, o mesmo ocorrendo com trabalhadores de 40 anos ou mais. Vinte trabalhos foram realizados a partir de documentos de domínio público (incluindo o Estatuto do Idoso e livros de literatura), sendo que dez foram caracterizados como estudos de revisão. Por fim, oito pesquisas analisaram a mídia e uma estudou uma determinada home page.

Com relação à área de estudos em que foram defendidas as dissertações, houve o predomínio da Gerontologia e da Psicologia (36 e 35 pesquisas, respectivamente). Dezessete trabalhos eram da Educação e doze, da Enfermagem. Foram encontrados nove estudos da Saúde Pública/Saúde Coletiva e número idêntico no Serviço Social. Mestrados na temática também foram realizados em Sociologia (sete), Educação Física (seis), Ciências Humanas (cinco) e Letras (cinco). Quatro dissertações foram defendidas em cada uma das seguintes áreas: Antropologia, Ciências Sociais, Comunicação, Direito e Saúde. Na Geografia havia duas pesquisas e foi encontrada apenas uma dissertação em: Administração; Cultura e Artes; Linguística, Letras e Artes; Ciências Políticas; Cognição e Linguagem; Ciências da Informação; Extensão Rural; Fisioterapia e Terapia Ocupacional; Políticas Públicas; Fonoaudiologia; e, Interdisciplinar.

A partir da análise do material selecionado foram criadas as seguintes categorias: Diferentes sentidos da velhice; Fatores psicossociais e envelhecimento saudável; Imagem corporal na velhice; Mídia e envelhecimento; Família e Idoso; Qualidade de vida na velhice; Direitos do Idoso; Memória e velhice; Informática e envelhecimento; e, Outras questões pertinentes ao processo de envelhecimento. Abaixo será abordada cada categoria, apontando o número de trabalhos a ela relacionados, dando exemplos extraídos dos resumos analisados e traçando considerações a respeito.

\section{Diferentes sentidos da velhice}

Nos 175 resumos estudados, foram encontradas 105 dissertações que problematizavam a respeito de o que é ser idoso e quais os sentidos da velhice na contemporaneidade. Pode-se ver isso na perspectiva da própria pessoa, conforme o seguinte exemplo: "As representações que os sujeitos possuem acerca da velhice e, em consequência, de si mesmos, relacionam-se com a maneira peculiar como cada sujeito organiza seu curso de vida, a partir das suas circunstâncias históricoculturais e da maneira como percebem a perda de seu papel profissional e social"14.

De acordo com Martins ${ }^{15}$, a velhice pode ser vista como algo positivo (sabedoria e tempo de vida) ou negativo (depressão, solidão, tristeza, doença e morte) e que isso irá depender "da cabeça e do espírito" de cada um. Dessa maneira, "o envelhecer é um processo individual, e que é vivido e construído conforme a experiência pessoal" ${ }^{16}$, sendo a velhice "um construto social produzido sob o efeito das influências culturais, sociais e políticas"17. Assim, "os significados atribuídos à velhice são construídos e reelaborados, indicando interpenetração das classificações de gênero, geração e classe social"18.

Observou-se, de modo geral nos trabalhos selecionados, que esse momento de vida ainda é ligado a bastantes fatores negativos, tais como doença, depressão, solidão, entre outros. Porém, também percebe-se que o ser idoso e o próprio processo de envelhecimento não são algo em si, constructos herméticos, prontos e determinados, mas que são produzidos nas relações sociais, ou seja, o fato de alguém ser um idoso ativo ou dependente, alegre ou amargurado, é traçado ao longo da vida do mesmo, de como essa pessoa foi produzindo ativamente sua vida, no contexto histórico, cultural, político e social em que vive.

Os atributos positivos relacionados à velhice aparecem no estudo de Mattner ${ }^{19}$, que comparou o discurso sobre o envelhecimento em crianças e idosos. A autora concluiu que para os dois grupos estudados há uma compreensão ambígua a respeito da velhice: ela está diretamente relacionada ao adoecimento, às perdas, às limitações e à exclusão social, mas, concomitantemente, é vista como algo bom, gratificante e sinônimo de estabilidade.

De acordo com Ragazzi ${ }^{20}$, na literatura infantil existe um estereótipo de debilidade relacionado à velhice. Nela, a pessoa é vista como sozinha, "caduca", entre outras coisas, e assim se constrói 
e se afirma esse sentido. De acordo com a autora, muitas vezes é por meio da literatura que a criança tem o primeiro contato com a velhice.

Essa valoração negativa é encontrada também em vários outros textos, em poesia e prosa, destinado a pessoas de outras faixas etárias, tais como os clássicos Rei Lear, de Shakespeare ${ }^{21}$, e O Avarento, de Molière ${ }^{22}$. Por outro lado, há também a afirmação de aspectos positivos, tal como no poema "A velhice", de Olavo Bilac ${ }^{23}$.

Ainda a esse respeito três dissertações discorriam sobre a visão dos universitários sobre a velhice. Estas deixam claro que, apesar de predominar uma conotação positiva em relação ao processo de envelhecimento e aos idosos, esse ainda não é um sentido único, pois, ora o idoso é visto como fonte de conhecimento, ora como problema e fonte de doença. Essas dissertações permitem perceber que o acesso a uma formação de nível superior não eximiu essas pessoas de reafirmarem aspectos bastantes negativos vinculados ao tema aqui estudado.

Esta ambivalência, sentidos positivos e negativos, também foi encontrada nas 10 dissertações que ouviram profissionais de saúde. Dentre elas Murta ${ }^{24}$, que diz: "Quanto à velhice, os profissionais a viam como conflituosa (positiva quando vista pelo tempo vivido; negativa pela perda da autonomia e independência)". Bimbato ${ }^{25}$, por sua vez, aponta que essa divergência ocorre em função da formação, da idade e da experiência de vida dos entrevistados. Além disso, ainda de acordo com essa autora, os trabalhadores da saúde não estão devidamente qualificados para o cuidado que deve ser prestado a essa parcela da população: "os profissionais encontram-se despreparados para enfrentar o grande desafio de melhorar o atendimento oferecido pelo serviço de saúde, principalmente, em se levando em consideração o aumento acentuado do número de idosos neste país" 25 .

Apesar de "velhice", "idosos" e "envelhecimento" serem termos polissêmicos, nos trabalhos analisados ainda está presente uma polaridade entre qualificadores positivos e negativos a eles relacionados. Reafirmam-se, assim, os escritos de Bosi ${ }^{1}$ e Papalia e Olds ${ }^{3}$ a respeito da temática em questão. Muitas conquistas foram feitas no sentido de buscarem assegurar um maior reconhecimento e valorização dessas pessoas, tais como a Política Nacional do Idoso $^{10}$, a Política Nacional de Saúde da Pessoa Idosa ${ }^{11}$, o Estatuto do Idoso ${ }^{12}$ dentre outros. Porém, mesmo assim, persistem atributos negativos que existiam antes destes documentos.

\section{Influência de fatores psicossociais no envelhecimento saudável}

Oito dissertações recuperadas pelo descritor idoso abordam os aspectos psicossociais que envolvem a velhice, apontando que, para além da questão etária, o fundamental é aquilo que as pessoas fazem (ou não) em seus relacionamentos, em sua vida diária. Não há, portanto, uma relação direta entre envelhecimento e solidão, depressão, diminuição da autoestima, como comumente se pensa.

Mas que esses problemas podem ser decorrência de como essas pessoas se reconhecem e são reconhecidas pela sociedade. "O significado e a relação são diferentes para cada pesquisado, mas fortemente relacionadas à esfera existencial. O envelhecimento do corpo não é impedimento para que estes idosos possam fazer planos e ir em busca de suas realizações" ${ }^{26}$.

Assim, para eles, o envelhecimento do corpo não necessariamente influi de maneira negativa em suas vidas, como também não os impedem de realizar sonhos.

Capitanini $^{27}$, por sua vez, afirma que "o sentimento de solidão não está associado ao viver só [...] amigos e capacidades pessoais de autonomia e envolvimento religioso constituem o maior suporte social e de bem estar", esclarecendo que envelhecer não é sinônimo de solidão. O envelhecimento saudável também é abordado em dez dissertações relacionadas à escolaridade e o exercitar de determinadas funções cognitivas, tal como no trabalho de Garcia ${ }^{28}$, que afirma o mérito da educação e da memória na consolidação da velhice bem sucedida.

Dessa forma, nas dissertações analisadas o envelhecimento saudável está intimamente interligado a fatores psicossociais e que as relações interpessoais e a inserção em grupos e atividades que estimulem o desenvolvimento cumprem papel importante para o seu alcance.

\section{Imagem corporal na terceira idade}

Quinze dissertações encontradas tratam da imagem corporal e das perdas que ocorrem com o processo de envelhecimento. É possível perceber que hoje se cultua a juventude e o corpo jovem, havendo uma valorização cada dia maior da cirurgia plástica para diminuir ou extinguir os traços típicos do envelhecer ${ }^{29}$.

Em antítese, o corpo do idoso é plenitude para alguns autores, ou seja, uma vitória pela pessoa ter conseguido chegar a uma idade avan- 
çada, um ideal que na atualidade deveria ser cada vez mais buscado. Sobre essa questão, Blessma ${ }^{30}$ diz: "o significado do corpo na velhice não está no que ele é, mas no que ele representa, ele exalta a vida e suas inúmeras possibilidades".

Assim, observa-se que não existe um consenso sobre o que é a velhice e de como são os corpos dos idosos, havendo sentidos heterogêneos na nossa sociedade atual. Ratificando, portanto, a afirmação de Neri e Debert ${ }^{4}$ : ora se valoriza a juventude, em detrimento da velhice; ora o corpo velho é visto como algo pleno, como uma vitória.

\section{Mídia e envelhecimento}

Outro assunto presente nas dissertações foi a relação entre mídia e envelhecimento, explicitando-se a influência que a primeira tem sobre a sociedade. Foram selecionados oito trabalhos, sendo que os autores mostram o "peso" que a publicidade tem sobre a construção da imagem dos idosos na sociedade, assim como afirmam que ela dita padrões para/sobre a velhice. Deixam claro o poder que a mídia tem de construir e desconstruir a imagem do idoso, impondo a ele o consumismo, como uma forma de aproximá-los da juventude.

Para Soares ${ }^{31}$ : "a publicidade conclama ao velho ser cidadão de consumo e neste contexto o consumo é parte de uma maneira de permanecer e/ou resgatar a juventude assim como estar jovem é estar apto a consumir”. Já, de acordo com Rodrigues $^{32}$ a mídia tem um grande poder de construir estereótipos e, por meio da propaganda, ela impõe valores, identidades e padrões às pessoas idosas.

Os estudos retomam questão importante que vem sendo debatida no campo da saúde: o poder da mídia na construção dos fatos, de nossa realidade, criando modos de ser, agir e pensar. Destaca-se novamente aqui o trabalho de Debert ${ }^{5}$, que auxilia a refletir a respeito daquilo que ela denomina a "reprivatização da velhice": a hipervalorização da juventude como ideal de vida e o envelhecimento como um ônus provocado pela pessoa. Ter-se-ia, assim, o entendimento de que o idoso seria o culpado pelo seu próprio envelhecimento, por não ter seguido à risca normas de autocuidado em relação à saúde e à estética, tão apregoados por muitos profissionais da saúde e amplamente divulgados na mídia.

\section{Família e idosos}

Foram encontradas sete dissertações que abordam a relação familiar com os idosos, ou seja, falam da convivência e das dificuldades, dentre outros fatores, que englobam essa relação, além de mostrar a importância da família para eles. Aponta-se tanto a importância que a família e o morar junto com a mesma tem para os ido$\operatorname{sos}^{33}$, quanto a violência sofrida, destacando-se que a maior ocorrência desta se dá dentro da própria residência, feita por membro da famí$\operatorname{lia}^{34}$. Portanto, observa-se nas dissertações analisadas que a família ainda tem papel primordial na vida dos idosos, reafirmando-se ainda que a família normalmente possui caráter positivo na vida desses.

Por outro lado, são necessários estudos que contribuam para a elucidação das problemáticas familiares e que colocam o idoso como alvo de violência, para que se possa diminuir a sua incidência ou até mesmo extingui-la.

\section{Qualidade de vida na terceira idade}

Por meio da análise dos resumos das 14 dissertações que trataram a respeito de qualidade de vida, percebe-se que a qualidade de vida na velhice é um processo amplo que depende de diversos fatores, como: independência, autonomia, vida saudável, alimentação, sono, além de destacarem as atividades de lazer, a participação nos grupos de promoção de saúde e os bons relacionamentos. No estudo de Moreira ${ }^{35}$ a qualidade de vida está diretamente ligada ao trabalho. Já, nos de Gomes ${ }^{36}$ e Tahan ${ }^{37}$, está vinculada à participação em práticas grupais, ou seja, em grupos de convivência, universidade da maior idade, grupos de dança, dentre outras práticas sociais.

O pertencimento a um grupo, apesar de nem sempre estar explicitamente relacionado à qualidade de vida, é tido como importante, tal como atesta o trabalho de Gomes ${ }^{38}$ : "As práticas grupais têm sido fundamentais na construção do presente, na projeção do futuro, enfim, na recondução dos cursos de vida na velhice, não só individual, mas de toda uma geração”.

Em síntese, a qualidade de vida na velhice é algo amplo e interligado a diversos fatores pessoais e interpessoais, dando-se grande importância à participação em atividades em grupos. 


\section{Direito do idoso}

Tema intrinsecamente relacionado ao tópico anterior, a proteção e a efetivação de direitos (saúde, moradia, alimentação adequada e lazer) foi abordada em sete trabalhos. Abrangeram-se aqui as questões relacionadas à cidadania e ao Estatuto do Idoso, destacando a importância e a influência desse documento na contemporaneidade.

De acordo com Silva ${ }^{39}$ o Estatuto do Idoso "propicia o estabelecimento de novas e enriquecedoras perspectivas para um envelhecimento digno, com o objetivo de influenciar decisivamente na obtenção de mudanças significativas para o resgate da ética, dos direitos e da dignidade da pessoa humana". Ainda sobre o Estatuto, Martins $^{40}$ afirma que o conhecimento dos direitos dos idosos independe de fatores como idade, renda e escolaridade, porém, apesar da maioria saber de sua existência, na prática seus benefícios não estão sendo sentidos por todos eles.

Muitos são os desafios que resultam do envelhecimento de uma população, especialmente de uma parcela que necessita de um sistema de proteção face à vulnerabilidade, o que impõe a manutenção, a ampliação e a sedimentação das conquistas do Estatuto do Idoso, buscando-se consolidar um Estado de Bem Estar Social que torne efetiva a cidadania.

Ainda no escopo de trabalhos relacionados diretamente aos direitos e à cidadania, foram encontradas duas dissertações que tratam da Política de Saúde do Idoso no SUS, e que afirmam ainda ser necessária a sensibilização dos gestores com relação a esse grupo social, com a implantação de programas e projetos, efetivação das políticas de atenção com medidas de promoção, prevenção e preservação da capacidade funcional com autonomia.

Assim, com base nas dissertações analisadas, percebe-se que a criação de leis, normas, orientações teóricas e políticas são importantes, mas não assegura, por si só, a melhoria nas condições de vida das pessoas. São também fundamentais práticas que as coloquem em pleno exercício, o que implica não só na sua divulgação e conhecimento, mas no engajamento de pessoas, grupos e instituições em prol da sua consolidação para que seja possível alcançar uma sociedade cujos membros tenham acesso, direito e exerçam uma velhice digna.

\section{Memória e velhice}

Cinco dissertações tratam sobre a importância da história de vida e da memória, tanto para a vida do idoso, como para a das pessoas que os cercam. O estudo de Antunes ${ }^{41}$ é esclarecedor nesse aspecto: "os velhos têm função social pelo fato de serem detentores de informações históricas, que uma vez divulgadas a comunidade podem exercer importante papel agregador e educacional." Ainda a esse respeito, Ribeiro ${ }^{42}$ afirma que as memórias dos idosos ajudam na construção da história, ao mesmo tempo em que o fato de lembrar e contar seu passado estimula suas mentes.

Assim, nas dissertações analisadas, há uma reafirmação dos estudos de Bosi ${ }^{1}$, ao perceberem a importância dos idosos na construção da história, da memória social e das próprias sociabilidades.

\section{Informática e envelhecimento}

Em número menor, duas dissertações tratavam da importância do ensino de informática para uma melhor adaptação do idoso no mundo contemporâneo, mostrando a importância do conhecimento da informática para seu bem estar e para um envelhecimento saudável.

Atualmente se reconhece que a inserção dos idosos no mundo digital é uma das possibilidades de inclusão social. E os estudos não somente trazem a relevância disso, mas também ratificam os de desenvolvimento, os quais postulam que em todos os ciclos de vida há a possibilidade de ganhos ${ }^{3,4}$.

\section{Outras questões pertinentes ao processo de envelhecimento}

Foram encontrados trabalhos únicos versando sobre temas diversos: como o idoso busca superar as adversidades e manter o senso de integridade; a identificação e a descrição das mudanças mais significativas (autorreferidas e autoavaliadas nas dimensões biológicas, sociais e psicológicas) ocorridas na velhice e seu impacto sobre o estado bem-estar subjetivo; e, sobre a negação da velhice pelo próprio idoso. Em relação a esta última, foi encontrada uma dissertação como contraponto, a qual discorria a respei- 
to de como os idosos são conscientes da sua condição, e estão em constante adaptação ao meio, sempre mostrando interesse nos mecanismos que a sociedade cria e oferece de modo a lhes facilitar o cotidiano, mostrando assim que os idosos podem ter grande capacidade de resiliência.

\section{Conclusão}

De início foi possível perceber que várias são as terminologias utilizadas para tratar as pessoas no ciclo de vida estudado, sendo os termos idoso, velho e terceira idade bastante utilizados nos resumos das dissertações analisadas. Porém, observa-se que a palavra idoso é a que aparece com mais frequência. $\mathrm{O}$ que talvez se deva ao fato de documentos de domínio público importantes, tais como a Política Nacional de Saúde do Idoso $^{11}$ e o Estatuto do Idoso ${ }^{12}$ terem adotado esse termo.

$\mathrm{Na}$ maior parte das dissertações ocorre o uso de mais de um termo, indistintamente, como na dissertação de Moreira ${ }^{35}$ que afirma: "discutir algumas relações existentes entre o trabalho e a qualidade de vida na terceira idade. [...] o trabalho pode ser uma fonte de aumento da qualidade de vida por proporcionar ao idoso a atividade, tanto física quanto intelectual". Porém, foi identificado um trabalho onde se propõe diferentes sentidos para os termos velho e idoso: "as pessoas, na continuidade da vida, não querem ser velhas (o indesejado), mas tornarem-se idosas (envelhecer com bem-estar)" ${ }^{\prime 4}$.

Além disso, é importante ressaltar que o maior número de dissertações encontradas inicialmente tratava de temas variados, sendo que em grande parte abordavam temas relacionados a doenças e medicamentos voltados a patologias mais comuns na velhice. Conforme foi explicado oportunamente, uma vez que elas fugiam do objetivo, não foram analisadas.

Já, a respeito das dissertações consideradas relevantes para a presente pesquisa, a maior parte delas permitiu entender os sentidos que são atribuídos aos idosos. Apesar de predominar ainda uma conotação negativa relacionada a eles e ao processo de envelhecimento, é possível concluir que há um aumento progressivo de pesquisas sobre o assunto, na época estudada, contribuindo para a visibilidade e a afirmação de seus aspectos positivos.

Não há um pensar, uma imagem, um sentido único e fixo sobre o idoso, mas diversos sentidos possíveis coexistindo, sendo constructos forjados de acordo com fatores históricos, sociais, econômicos e culturais. Existem, assim, múltiplos sentidos e maneiras de se entender, explicar e viver a velhice. Não existe um consenso do que é ser idoso e nem de quando se começa a sêlo. Para Beauvoir ${ }^{44}$, a velhice já foi vista como algo vergonhoso para sociedade, porém, é notório que esses discursos vêm mudando ao longo dos anos.

Apesar disso, perdura a incessante busca da eterna juventude, e que essa procura interminável tem sido estimulada pela sociedade de maneira geral, incluindo e destacando-se nisso a mídia. A juventude como um bem de consumo é hipervalorizada $^{45}$ ao mesmo tempo em que ser idoso tem sido também arguido como uma incompetência pessoal ${ }^{5}$.

Muitos temas têm sido abordados nas dissertações de mestrado relacionados ao processo de envelhecimento e aos idosos e, com a análise dos resumos, percebeu-se que o interesse por essas pessoas vem aumentando ao longo dos últimos 10 anos. Apesar disso, ainda existem pouco trabalhos que tratam de qualidade de vida, e de como os idosos atribuem sentido a esse momento de suas vidas, ou seja, poucos dão voz a essa população. Este é um aspecto dessa área de estudo que ainda merece maior interesse por parte dos pesquisadores, já que a maioria dos estudos então concentrados na doença e nos diversos aspectos que as englobam.

Ainda nesse quesito, destaca-se a importância do trabalho de pesquisa realizado pela Organização Mundial de Saúde que, ouvindo idosos de todo o mundo, publicou o "Guia Global Cidade Amiga do Idoso", expõe os questionamentos e as preocupações destes em relação à vida urbana, além de orientações a respeito de como as pessoas e as cidades podem se organizar de maneira a promover a inclusão de idosos com diferentes necessidades e graus de capacidade, propiciando um envelhecimento saudável aos mesmos $^{46}$.

Para além da questão etária, o fundamental é o entendimento de que as pessoas produzem ativamente as suas vidas, em sua jornada diária. Não há, portanto, uma relação direta entre envelhecimento e problemas de saúde, como comumente se pensa, resguardadas as perdas inerentes à idade avançada. A trajetória de vida das pessoas, incluindo as condições em que viveram, o acesso e a possibilidade de desfrutar de seus direitos como cidadão, a inserção, a proteção e o apoio familiar e da sociedade, assim como as maneiras de enfrentamento e de resolução dos 
problemas surgidos nos diversos âmbitos da vida, desempenham papel fundamental na obtenção ou não de envelhecimento saudável.

Os sentidos que os idosos atribuem a si mesmos e ao processo de envelhecimento, assim como aqueles atribuídos por outrem fazem toda a diferença, pois contribuirão na realização ou na ausência de investimentos tanto pessoais quanto familiares e da sociedade nessas pessoas. O idoso em muito se beneficia, para ter um envelhecimento saudável e digno, do cuidado e da proteção da família e de desfrutar de amizades, desenvolvendo suas capacidades ainda existentes e inserindose nas atividades possíveis como cidadão.

Para isso torna-se também importante não somente a divulgação, mas o acesso e o exercício dos direitos conquistados nas legislações específicas voltadas a essa população. Há de se reconhecer a importância dos idosos em nossa sociedade, pois, além de tudo o que foi afirmado, eles desempenham um importante papel na construção da memória da humanidade.

\section{Colaboradores}

Ambos autores foram responsáveis pela proposta da pesquisa e pela redação do artigo. MA Hein foi responsável pela execução dos procedimentos para alcance dos objetivos, pela categorização e análise dos dados. SS Aragaki foi responsável pela orientação da pesquisa.

\section{Referências}

1. Bosi E. Memória e sociedade: lembranças de velhos. $5^{a}$ ed. São Paulo: Companhia das Letras; 2007.

2. Hall G. Senescence: The Last Half of Life. New York: D. Appleton and Company; 1922.

3. Papalia DE, Olds SW. Desenvolvimento Humano. 7a ed. Porto Alegre: Artes Médicas; 2000.

4. Neri AL, Debert GG. Velhice e Sociedade. Campinas: Papirus; 1999.

5. Debert GG. A reinvenção da velhice: socialização e processos de reprivatização do envelhecimento. São Paulo: EDUSP/FAPESP; 1999.

6. Haraway D. Conocimientos situados: la cuestión científica en el feminismo y el privilegio de la perspectiva parcial. In: Haraway D. Ciência, cyborg y mujeres: la reinvención de la naturaleza. Madrid: Instituto de La Mujer; 1991.

7. Gergen K. The Social Construction Movement in Modern Psychology. American Psychologist 1985; 40(3):266-275.

8. Marques AM. Velho/Idoso: construindo o sujeito da terceira idade. Rev Esboços [periódico internet]. 2004[acessado 2012 jan 30]; 11(11): [cerca de 7 p.]. Disponível em: http://www.periodicos.ufsc.br/ index.php/esbocos/article/view/336/9870

9. Rodrigues LS, Soares GA. Velho, idoso e terceira idade na sociedade contemporânea. Rev Ágora [periódico internet]. 2006[ acessado 2012 jan 30]; 4(4): [cerca de 29 p.]. Disponível em: http://www.ufes.br/ ppghis/agora/Documentos/Revista_4_PDFs/Lizete \%20de\%20Souza $\% 20$ Rodrigues $\% 20-\% 20 \%$ C3\%81 gora_4.pdf 
10. Brasil. Lei no 8.842 , de 4 de Janeiro de 1994. Dispõe sobre a Política Nacional do Idoso, cria o Conselho Nacional do Idoso e dá outras providências. Diário Oficial da União 1994; 4 jan.

11. Brasil. Ministério da Saúde. Portaria no 2.528 de 19 de outubro de 2006. Política Nacional de Saúde da Pessoa Idosa. Diário Oficial da União 2006; 19 out.

12. Brasil. Lei no 10.741, de 10 de outubro de 2003. Dispõe sobre o Estatuto do Idoso e dá outras providências. Diário Oficial da União 2003; 10 out.

13. Spink P. Análise de documentos de domínio publico. In: Spink MJ, organizadora. Práticas Discursivas e Produção de Sentidos no Cotidiano: aproximações Teóricas e Metodológicas. São Paulo: Cortez; 1999. p. 123-154.

14. Gomes MQC. Velhas e Velhos: A Busca de Novos Espaços de Sociabilidade [dissertação]. Salvador: Universidade Federal da Bahia; 2001.

15. Martins CRM. O envelhecer segundo adolescentes, adultos e idosos usuários do SESC Maringá: um estudo de Representações Sociais [dissertação]. Florianópolis: Universidade Federal de Santa Catarina; 2002.

16. Ferraz LA. Envelhecimento: reflexões partir de uma experiência em grupo [dissertação]. São Paulo: Pontifícia Universidade Católica de São Paulo; 2003.

17. Lima HC. A velhice sob o olhar de idosos retoricistas [dissertação]. Recife: Universidade Federal de Pernambuco; 2003.

18. Souza CMB. Envelhecimento e Tendências de Sociabilidade: identidades de gênero e de classe social em grupos de idosos [dissertação]. Salvador: Universidade Federal da Bahia; 2003.

19. Mattner AE. A ambigüidade no processo de envelhecimento [dissertação]. Porto Alegre: Pontifícia Universidade Católica do Rio Grande do Sul; 2004.

20. Ragazzi GA. Imagem da Velhice na Literatura Infantil [dissertação]. São Paulo: Pontifícia Universidade Católica de São Paulo; 2004.

21. Shakespeare W. Rei Lear. $1^{\text {a }}$ ed. São Paulo: Scipione; 2002.

22. Molière JBP. O Avarento. $1^{\text {a }}$ ed. Curitiba: FTD; 2007.

23. Bilac O. Poesias Infantis. Rio de Janeiro: Francisco Alves; 1929/2009.

24. Murta NMG. A Velhice ao Olhar da Equipe do Programa Saúde da Família em Diamantina /Mg [dissertação]. São Paulo: Pontifícia Universidade Católica de São Paulo; 2005.

25. Bimbato AMJ. A representação de velhice entre os profissionais que atuam nos Núcleos de Saúde da Família [dissertação]. Ribeirão Preto: Universidade de São Paulo/Ribeirão Preto; 2008.

26. Monteiro PP. Envelhecimento: Imagem e Transformação Corporal [dissertação]. São Paulo: Pontifícia Universidade Católica de São Paulo; 2000.

27. Capitanni ME. Sentimento de solidão, bem estar subjetivo e relações sociais em idosas vivendo sós [dissertação]. Campinas: Universidade Estadual de Campinas; 2000.

28. Garcia TFM. Envelhecimento, educação permanente e memória: caminho para a consolidação do envelhecimento bem sucedido [dissertação]. Ceará: Universidade Federal do Ceará; 2004.

29. Melo RLS. Auto-imagem abalada: o significado do rejuvenescimento para um corpo que envelhece [dissertação]. São Paulo: Pontifícia Universidade Católica de São Paulo; 2008.
30. Blessma EJ. Corporeidade e envelhecimento: o significado do corpo na velhice [dissertação]. Porto Alegre: Universidade Federal do Rio Grande do Sul; 31. 2003.

Soares R. Jovens de 60 e publicidade: identidade discursiva do sexagenário na publicidade [dissertação]. Pernam-

32. buco: Universidade Federal de Pernambuco; 2007. Rodrigues PKA. O discurso da publicidade brasileira: construção e desconstrução de estereótipos da velhice [dissertação]. São Paulo: Pontifícia Universi-

33. dade Católica de São Paulo; 2008. Campos EO. O Idoso e a Família [dissertação]. Rio

34. de Janeiro: Universidade Gama Filho; 2002. Figueiredo UCS. O abuso na velhice a partir do olhar de pessoas idosas [dissertação]. Ribeirão Preto: Uni-

35. versidade de São Paulo/ Ribeirão Preto; 2000. Moreira MMS. Trabalho, Qualidade de Vida e Envelhecimento [dissertação]. Rio de Janeiro: Fundação

36. Oswaldo Cruz; 2000.

Gomes A. Psicologia Atividade e envelhecimento: representações sociais de um grupo de idosos [dissertação]. Vitória: Universidade Federal do Espíri-

37. to Santo; 2000.

Tahan J. Envelhecimento e Qualidade de Vida: Significados para idosos participantes de Grupos de Promoção de Saúde no contexto da Estratégia Saúde da Família [dissertação]. Ribeirão Preto: Universi-

38. dade de São Paulo/ Ribeirão Preto; 2009.

Gomes MQC. Velhas e Velhos: A Busca de Novos Espaços de Sociabilidade [dissertação]. Salvador:

39. Universidade Federal da Bahia; 2001.

Silva SS. Estatuto do Idoso: um crítico e novo olhar sobre o idoso e os desafios a serem enfrentados [dissertação]. Marília: Fundação de Ensino "Eurí-

40. pides Soares da Rocha"; 2007. Martins MS. Conhecimento de idosos sobre seus direitos [dissertação]. São Paulo: Universidade de São

41. Paulo; 2008.

Antunes DC. Memória das transformações de grupos comunitários como forma de favorecimento do envelhecimento bem-sucedido [dissertação]. Campinas:

42. Universidade Estadual de Campinas; 2006. Ribeiro MHS. Histórias de Vida e de Leitura: memórias da terceira idade [dissertação]. Salvador: Uni-

43. versidade Federal da Bahia; 2009.

Santana RF. O envelhecer na dimensão imaginativa: ser idoso e ser velho [dissertação]. Rio de Janeiro:

44. Universidade do Estado do Rio de Janeiro; 2004. Beauvoir S. A velhice. 5a Ed. Rio de Janeiro: Nova

45. Fronteira; 2003.

Homem LS. A criança eterna. Rev Facom [periódico na Internet]. 2009 Jan-Jun [acessado 2011 Jul 12]; 21: [cerca de 10 p.]. Disponível em: http://www.faap.br/

46. revista_faap/revista_facom/facom_21/maria.pdf Organização Mundial em Saúde. Guia Global: Cidade amiga do idoso. Rio de janeiro: Fundação Calouste Gulbenkian; 2009.

Artigo apresentado em 07/09/2011

Aprovado em 23/02/2012

Versão final apresentada em 08/03/2012 